\title{
Existence, well-posedness of coupled fixed points and application to nonlinear integral equations
}

\author{
Binayak S. ChOUdhurY ${ }^{1}$ \\ Nikhilesh Metiya ${ }^{2}$ \\ Sunirmal Kundu ${ }^{3}$ \\ 1 Department of Mathematics, \\ Indian Institute of Engineering \\ Science and Technology, Shibpur, \\ Howrah-711103, West Bengal, \\ India. \\ binayak12@yahoo.co.in \\ ${ }^{2}$ Department of Mathematics, \\ Sovarani Memorial College, \\ Jagatballavpur, Howrah-711408, \\ West Bengal, India. \\ metiya.nikhilesh@gmail.com \\ 3 Department of Mathematics, \\ Government General Degree \\ College, Salboni, Paschim \\ Mednipur-721516, West Bengal, \\ India. \\ sunirmalkundu2009@rediffmail.com
}

\section{ABSTRACT}

We investigate a fixed point problem for coupled Geraghty type contraction in a metric space with a binary relation. The role of the binary relation is to restrict the scope of the contraction to smaller number of ordered pairs. Such possibilities have been explored for different types of contractions in recent times which has led to the emergence of relational fixed point theory. Geraghty type contractions arose in the literatures as a part of research seeking the replacement contraction constants by appropriate functions. Also coupled fixed point problems have evoked much interest in recent times. Combining the above trends we formulate and solve the fixed point problem mentioned above. Further we show that with some additional conditions such solution is unique. Well-posedness of the problem is investigated. An illustrative example is discussed. The consequences of the results are discussed considering $\alpha$-dominated mappings and graphs on the metric space. Finally we apply our result to show the existence of solution of some system of nonlinear integral equations.

\section{RESUMEN}

Investigamos un problema de punto fijo para contracciones acopladas de tipo Geraghty en un espacio métrico con una relación binaria. El rol de la relación binaria es restringir el alcance de la contracción a un número menor de pares ordenados. Tales posibilidades han sido exploradas para diferentes tipos de contracciones recientemente, lo que ha conllevado el nacimiento de la teoría de punto fijo relacional. Las contracciones de tipo Geraghty aparecen en la literatura como parte de la investigación buscando reemplazar las constantes de contracción por funciones apropiadas. También problemas de puntos fijos acoplados han sido de mucho interés recientemente. Combinando las ideas anteriores, formulamos y resolvemos el problema de punto fijo mencionado anteriormente. Más aún, mostramos que bajo condiciones adicionales tal solución es única. Se investiga la bien-definición del problema. Se discute un ejemplo ilustrativo. Las consecuencias de los resultados se discuten considerando aplicaciones $\alpha$-dominadas y grafos en espacios métricos. Finalmente aplicamos nuestros resultados para mostrar la existencia de soluciones de algunos sistemas de ecuaciones integrales no lineales.

Keywords and Phrases: Metric space; coupled fixed point; well-posedness; application.

2020 AMS Mathematics Subject Classification: 54H10, 54H25, 47H10. 


\section{Introduction}

Coupled fixed point results constitute a domain in metric fixed point theory which has experienced rapid development in recent times. The concept of coupled fixed point was introduced some time back in 1987 by Guo et al [17]. But only after the publication of the work of Bhaskar et al [15] a large number of papers have been written on this topic and on topics related to it $[7,9,18,21]$.

Our consideration in this paper is a study related to fixed points of some coupled operators on metric spaces equipped with an appropriate binary relation. A contraction condition of Geraghty type $[20,26,32]$ is supposed to be satisfied by the coupled operator for those points which are related by the binary relation. As a consequence of it the assumption here is weaker than the usual case in metric fixed point theory where it is assumed that the inequality condition holds for arbitrarily chosen pairs from the space. Such weakening of conditions have substantially occupied recent interests in fixed point theory. Works of this category have come to be known as relationtheoretic fixed point results. Some instances of these works are in $[1,3,23,30]$.

We use Geraghty's approach [16] to define a coupled contraction condition. It is a part of research where the constants of the contractions are replaced by suitable control functions in order to make the contraction inequality more general. Such works occupy important positions in metric fixed point theory. Some instances of these works are [5, 9, 13, 14, 22].

In this paper we combine the above trends in fixed point theory to define a new problem and then investigate its several aspects and show one application of the result.

Firstly, we show that such problem has a solution, that is, a coupled fixed point of the concerned operator exists. The uniqueness of the coupled fixed point is established under some additional conditions.

Well-posedness has been considered for many fixed point problems in recent times [24, 25, 27, 28]. In the present paper we deal with the well-posedness of the problem mentioned above.

Next we discuss some consequences of our main result. Precisely we obtain some results for $\alpha$-dominated mappings and results in metric spaces having a graph defined on it. The main result is supported with an example. In the last section we include an application of the main theorem to a problem of nonlinear integral equations.

\section{Mathematical background}

In the following we discuss the necessary mathematics for the discussion on the topics in the following sections. Let $X$ and $Y$ be two nonempty sets and $R$ be a relation from $X$ to $Y$, that is, $R \subseteq X \times Y$. We write $(x, y) \in R$ or $x R y$ to mean $x$ is $R$ related to $y$. The set $P=\{x \in X:(x, y) \in$ 
$R$ for some $y \in Y\}$ is called the domain of $R$ and the set $Q=\{y \in Y:(x, y) \in R$ for some $x \in X\}$ is called the range of $R$. By $R^{-1}$ we mean the set $\{(y, x):(x, y) \in R\}$ which is called the inverse of $R$.

A relation $R$ from $X$ to $X$ is called a relation on $X$. Let $R$ be a relation on $X$. The relation $R$ is said to be directed if for given $x, y \in X$, there exists $z \in X$ such that $(x, z) \in R$ and $(y, z) \in R$. The relation $R$ is said to be a partial order relation on $X$ if it is reflexive, anti-symmetric and transitive.

Let $X$ be a nonempty set. An element $(x, y) \in X \times X$ is called a coupled fixed point of a function $F: X \times X \rightarrow X$ if $x=F(x, y)$ and $y=F(y, x)$.

Problem $(\mathrm{P})$ : Let $(X, d)$ be a metric space and $F: X \times X \rightarrow X$ be a mapping. We consider the problem of finding a coupled fixed point of $F$, that is, the problem of finding $(x, y) \in X \times X$ such that

$$
x=F(x, y) \text { and } y=F(y, x) .
$$

Definition 2.1 ([6]). The problem (P) is called well-posed if (i) $F$ has a unique coupled fixed point $\left(x^{*}, y^{*}\right)$, (ii) $x_{n} \rightarrow x^{*}$ and $y_{n} \rightarrow y^{*}$ as $n \rightarrow \infty$, whenever $\left\{\left(x_{n}, y_{n}\right)\right\}$ is any sequence in $X \times X$ for which $\limsup _{n \rightarrow \infty}\left[d\left(x_{n}, x^{*}\right)+d\left(y_{n}, y^{*}\right)\right]$ is finite and $\lim _{n \rightarrow \infty} d\left(x_{n}, F\left(x_{n}, y_{n}\right)\right)=$ $\lim _{n \rightarrow \infty} d\left(y_{n}, F\left(y_{n}, x_{n}\right)\right)=0$.

We define here the $R$-dominated mapping.

Definition 2.2. Let $X$ be a nonempty set with a binary relation $R$ on it. A mapping $F: X \times X \rightarrow$ $X$ is said to be $R$-dominated if $(x, F(x, y)) \in R$ and $(F(y, x), y) \in R$, for any $(x, y) \in X \times X$.

Example 2.3. Let $X=[0,1]$ be equipped with usual metric. Let $F: X \times X \rightarrow X$ be defined as $F(x, y)=\frac{x+y}{16+x+y}$, for $x, y \in X$. Let a binary relation $R$ on $X$ be defined as $R=\{(x, y): 0 \leq$ $x \leq 1 ; 0 \leq y \leq \frac{1}{8}$ or $\left.0 \leq x \leq \frac{1}{8} ; 0 \leq y \leq 1\right\}$. Then $F(x, y)=F(y, x) \in\left[0, \frac{1}{8}\right]$, for $x, y \in[0,1]$. It follows that $(x, F(x, y)) \in R$ and $(F(y, x), y) \in R$, for any $(x, y) \in X \times X$. Therefore, $F$ is a $R$-dominated mapping.

We introduce $R$-regularity condition in metric spaces.

Definition 2.4. Let $(X, d)$ be a metric space with a binary relation $R$ on it. Then $X$ is said to have regular property with respect to $R$ (or $R$-regular property) if for every sequence $\left\{x_{n}\right\}$ in $X$ converging to $x \in X,\left(x_{n}, x_{n+1}\right) \in R$, for all $n$ implies $\left(x_{n}, x\right) \in R$, for all $n$ [or $\left(x_{n+1}, x_{n}\right) \in$ $R$, for all $n$ implies $\left(x, x_{n}\right) \in R$, for all $n$ ].

The following class of functions has appeared in several recent works related to fixed point theory. 
Let $\gamma:[0, \infty) \rightarrow[0,1)$ be such that for any sequence $\left\{t_{n}\right\}$ in $[0, \infty), \lim _{n \rightarrow \infty} \gamma\left(t_{n}\right)=1$ implies $\lim _{n \rightarrow \infty} t_{n}=0$. We denote the collection all such functions $\gamma$ by $\boldsymbol{B}$. Such functions have appeared in several papers as for instances in $[20,32,33]$.

In our theorems, we use following class of functions:

Let $\beta:[0, \infty) \rightarrow[0,1)$ be such that for any sequence $\left\{t_{n}\right\}$ in $[0, \infty), \lim _{\sup _{n \rightarrow \infty}} \beta\left(t_{n}\right)=1$ implies $\lim _{n \rightarrow \infty} t_{n}=0$. We denote the collection all such functions $\beta$ by $\boldsymbol{B}^{*}$.

We have the following observation about the class $\boldsymbol{B}^{*}$. Our class $\boldsymbol{B}^{*}$ is more generalized than $\boldsymbol{B}$. From the definition of $\boldsymbol{B}$ and $\boldsymbol{B}^{*}$ it is clear that our class $\boldsymbol{B}^{*}$ contains $\boldsymbol{B}$ and this containment is proper. The following example makes the fact clear:

Example 2.5. Now consider the function $\beta:[0, \infty) \rightarrow[0,1)$ defined by

$$
\beta(t)=\left\{\begin{array}{cl}
\left|\frac{\sin t}{t}\right| & , \text { if } t \text { is irrational } \\
\frac{1}{2} & , \text { if } t \text { is rational. }
\end{array}\right.
$$

Clearly $\beta \in \boldsymbol{B}^{*}$ but $\beta \notin \boldsymbol{B}$.

\section{Main results}

In this section we establish a coupled fixed point result. We discuss its uniqueness under some additional conditions. We illustrate it with an example.

Theorem 3.1. Let $(X, d)$ be a complete metric space with a transitive relation $R$ on it such that $X$ has $R$-regular property. Suppose that $F: X \times X \rightarrow X$ is a $R$-dominated mapping and there exists $\beta \in B^{*}$ such that for $(x, y),(u, v) \in X \times X$ with $[(x, u) \in R$ and $(v, y) \in R]$ or $[(u, x) \in R$ and $(y, v) \in R]$,

$$
d(F(x, y), F(u, v)) \leq \beta(M(x, y, u, v)) M(x, y, u, v)
$$

where

$$
\begin{aligned}
M(x, y, u, v)= & \max \left\{\frac{d(x, u)+d(y, v)}{2}, \frac{d(x, F(x, y))+d(y, F(y, x))}{2},\right. \\
& \left.\frac{d(u, F(u, v))+d(v, F(v, u))}{2}, \frac{d(u, F(x, y))+d(v, F(y, x))}{2}\right\} .
\end{aligned}
$$

Then F has a coupled fixed point.

Proof. Let $\left(x_{0}, y_{0}\right) \in X \times X$ be arbitrary. We construct two sequences $\left\{x_{n}\right\}$ and $\left\{y_{n}\right\}$ in $X$ such that

$$
x_{n+1}=F\left(x_{n}, y_{n}\right) \text { and } y_{n+1}=F\left(y_{n}, x_{n}\right) \text {, for all } n \geq 0 \text {. }
$$


As $F$ is $R$-dominated, we have

$$
\left(x_{n}, F\left(x_{n}, y_{n}\right)\right)=\left(x_{n}, x_{n+1}\right) \in R \quad \text { and } \quad\left(F\left(y_{n}, x_{n}\right), y_{n}\right)=\left(y_{n+1}, y_{n}\right) \in R \text {, for all } n \geq 0 \text {. }
$$

Let

$$
r_{n}=d\left(x_{n}, x_{n+1}\right)+d\left(y_{n}, y_{n+1}\right), \text { for all } n \geq 0
$$

By (3.1), (3.2), (3.3) and (3.4), we have

$$
\begin{aligned}
d\left(x_{n+1}, x_{n+2}\right) & =d\left(F\left(x_{n}, y_{n}\right), F\left(x_{n+1}, y_{n+1}\right)\right) \\
& \leq \beta\left(M\left(x_{n}, y_{n}, x_{n+1}, y_{n+1}\right)\right) M\left(x_{n}, y_{n}, x_{n+1}, y_{n+1}\right)
\end{aligned}
$$

where

$$
\begin{aligned}
M\left(x_{n}, y_{n}, x_{n+1}, y_{n+1}\right)= & \max \left\{\frac{d\left(x_{n}, x_{n+1}\right)+d\left(y_{n}, y_{n+1}\right)}{2}, \frac{d\left(x_{n}, F\left(x_{n}, y_{n}\right)\right)+d\left(y_{n}, F\left(y_{n}, x_{n}\right)\right)}{2},\right. \\
& \frac{d\left(x_{n+1}, F\left(x_{n+1}, y_{n+1}\right)\right)+d\left(y_{n+1}, F\left(y_{n+1}, x_{n+1}\right)\right)}{2}, \\
& \left.\frac{d\left(x_{n+1}, F\left(x_{n}, y_{n}\right)\right)+d\left(y_{n+1}, F\left(y_{n}, x_{n}\right)\right)}{2}\right\} \\
= & \max \left\{\frac{d\left(x_{n}, x_{n+1}\right)+d\left(y_{n}, y_{n+1}\right)}{2}, \frac{d\left(x_{n}, x_{n+1}\right)+d\left(y_{n}, y_{n+1}\right)}{2},\right. \\
& \left.\frac{d\left(x_{n+1}, x_{n+2}\right)+d\left(y_{n+1}, y_{n+2}\right)}{2}, \frac{d\left(x_{n+1}, x_{n+1}\right)+d\left(y_{n+1}, y_{n+1}\right)}{2}\right\} \\
= & \max \left\{\frac{d\left(x_{n}, x_{n+1}\right)+d\left(y_{n}, y_{n+1}\right)}{2}, \frac{d\left(x_{n}, x_{n+1}\right)+d\left(y_{n}, y_{n+1}\right)}{2},\right. \\
& \left.\frac{d\left(x_{n+1}, x_{n+2}\right)+d\left(y_{n+1}, y_{n+2}\right)}{2}, 0\right\} \\
= & \max \left\{\frac{r_{n}}{2}, \frac{r_{n}}{2} \frac{r_{n+1}}{2}, 0\right\} \\
= & \max \left\{\frac{r_{n}}{2}, \frac{r_{n+1}}{2}\right\} .
\end{aligned}
$$

Therefore, from (3.5) and (3.6), we have

$$
d\left(x_{n+1}, x_{n+2}\right) \leq \beta\left(\max \left\{\frac{r_{n}}{2}, \frac{r_{n+1}}{2}\right\}\right) \max \left\{\frac{r_{n}}{2}, \frac{r_{n+1}}{2}\right\} .
$$

Similarly, we can show that

$$
d\left(y_{n+1}, y_{n+2}\right) \leq \beta\left(\max \left\{\frac{r_{n}}{2}, \frac{r_{n+1}}{2}\right\}\right) \max \left\{\frac{r_{n}}{2}, \frac{r_{n+1}}{2}\right\} .
$$

Combining (3.7) and (3.8), we have

$$
\begin{aligned}
r_{n+1} & =d\left(x_{n+1}, x_{n+2}\right)+d\left(y_{n+1}, y_{n+2}\right) \\
& \leq 2 \beta\left(\max \left\{\frac{r_{n}}{2}, \frac{r_{n+1}}{2}\right\}\right) \max \left\{\frac{r_{n}}{2}, \frac{r_{n+1}}{2}\right\} \\
& =\beta\left(\max \left\{\frac{r_{n}}{2}, \frac{r_{n+1}}{2}\right\}\right) \max \left\{r_{n}, r_{n+1}\right\} .
\end{aligned}
$$


Suppose that $0 \leq r_{n}<r_{n+1}$. From (3.9), we have

$$
r_{n+1} \leq \beta\left(\frac{r_{n+1}}{2}\right) r_{n+1}<r_{n+1}
$$

which is a contradiction. Therefore, $r_{n+1} \leq r_{n}$, for all $n \geq 0$, that is, $\left\{r_{n}\right\}$ is a decreasing sequence of nonnegative real numbers. Hence there exists $r \geq 0$ such that $r_{n} \rightarrow r$ as $n \rightarrow \infty$. By (3.9), we have

$$
r_{n+1} \leq \beta\left(\frac{r_{n}}{2}\right) r_{n}, \text { for all } n \geq 0 .
$$

If possible, suppose that $r>0$. Taking limit supremum in (3.10), we have

$$
r \leq \limsup _{n \rightarrow \infty} \beta\left(\frac{r_{n}}{2}\right) r,
$$

which implies that $1 \leq \lim \sup _{n \rightarrow \infty} \beta\left(\frac{r_{n}}{2}\right) \leq 1$, that is, $\limsup _{n \rightarrow \infty} \beta\left(\frac{r_{n}}{2}\right)=1$. Then it follows by the property of $\beta$ that $\lim _{n \rightarrow \infty} \frac{r_{n}}{2}=\frac{r}{2}=0$, that is, $r=0$ which contradicts our assumption. Hence $r=0$. Then we have

$$
\lim _{n \rightarrow \infty}\left[d\left(x_{n}, x_{n+1}\right)+d\left(y_{n}, y_{n+1}\right)\right]=\lim _{n \rightarrow \infty} d\left(x_{n}, x_{n+1}\right)=\lim _{n \rightarrow \infty} d\left(y_{n}, y_{n+1}\right)=0 .
$$

Now we prove that both $\left\{x_{n}\right\}$ and $\left\{y_{n}\right\}$ are Cauchy sequences. If possible, assume that either $\left\{x_{n}\right\}$ or $\left\{y_{n}\right\}$ fails to be a Cauchy sequence. Then

$$
\text { either } \lim _{m, n \rightarrow \infty} d\left(x_{m}, x_{n}\right) \neq 0 \text { or } \lim _{m \rightarrow \infty} d\left(y_{m}, y_{n}\right) \neq 0 \text {. }
$$

Hence,

$$
\lim _{m \rightarrow \infty}\left[d\left(x_{m}, x_{n}\right)+d\left(y_{m}, y_{n}\right)\right] \neq 0,
$$

that is, there exists $\epsilon>0$ for which we can find subsequences $\{m(k)\}$ and $\{n(k)\}$ of positive integers with $n(k)>m(k)>k$ such that

$$
d\left(x_{m(k)}, x_{n(k)}\right)+d\left(y_{m(k)}, y_{n(k)}\right) \geq \epsilon \text { and } d\left(x_{m(k)}, x_{n(k)-1}\right)+d\left(y_{m(k)}, y_{n(k)-1}\right)<\epsilon .
$$

Now,

$$
\begin{aligned}
\epsilon & \leq d\left(x_{n(k)}, x_{m(k)}\right)+d\left(y_{n(k)}, y_{m(k)}\right) \\
& \leq\left[d\left(x_{n(k)}, x_{n(k)-1}\right)+d\left(y_{n(k)}, y_{n(k)-1}\right)\right]+\left[d\left(x_{n(k)-1}, x_{m(k)}\right)+d\left(y_{n(k)-1}, y_{m(k)}\right)\right] \\
& <d\left(x_{n(k)}, x_{n(k)-1}\right)+d\left(y_{n(k)}, y_{n(k)-1}\right)+\epsilon .
\end{aligned}
$$

Taking limit as $k \rightarrow \infty$ in the above inequality and using (3.11), we have

$$
\lim _{k \rightarrow \infty}\left[d\left(x_{m(k)}, x_{n(k)}\right)+d\left(y_{m(k)}, y_{n(k)}\right)\right]=\epsilon .
$$

Again,

$$
\begin{aligned}
& d\left(x_{n(k)-1}, x_{m(k)-1}\right)+d\left(y_{n(k)-1}, y_{m(k)-1}\right) \\
& \leq\left[d\left(x_{n(k)-1}, x_{m(k)}\right)+d\left(y_{n(k)-1}, y_{m(k)}\right)\right]+\left[d\left(x_{m(k)}, x_{m(k)-1}\right)+d\left(y_{m(k)}, y_{m(k)-1}\right)\right] \\
& <\epsilon+\left[d\left(x_{m(k)}, x_{m(k)-1}\right)+d\left(y_{m(k)}, y_{m(k)-1}\right)\right] .
\end{aligned}
$$


Again,

$$
\begin{aligned}
& d\left(x_{n(k)}, x_{m(k)}\right)+d\left(y_{n(k)}, y_{m(k)}\right) \leq\left[d\left(x_{n(k)}, x_{n(k)-1}\right)+d\left(y_{n(k)}, y_{n(k)-1}\right)\right]+ \\
& {\left[d\left(x_{n(k)-1}, x_{m(k)-1}\right)+d\left(y_{n(k)-1}, y_{m(k)-1}\right)\right]+\left[d\left(x_{m(k)-1}, x_{m(k)}\right)+d\left(y_{m(k)-1}, y_{m(k)}\right)\right],}
\end{aligned}
$$

that is,

$$
\begin{aligned}
& d\left(x_{n(k)-1}, x_{m(k)-1}\right)+d\left(y_{n(k)-1}, y_{m(k)-1}\right) \geq d\left(x_{n(k)}, x_{m(k)}\right)+d\left(y_{n(k)}, y_{m(k)}\right) \\
& -d\left(x_{n(k)}, x_{n(k)-1}\right)-d\left(y_{n(k)}, y_{n(k)-1}\right)-d\left(x_{m(k)-1}, x_{m(k)}\right)-d\left(y_{m(k)-1}, y_{m(k)}\right) .
\end{aligned}
$$

From the above inequalities we have that

$$
\begin{aligned}
& d\left(x_{n(k)}, x_{m(k)}\right)+d\left(y_{n(k)}, y_{m(k)}\right)-d\left(x_{n(k)}, x_{n(k)-1}\right)-d\left(y_{n(k)}, y_{n(k)-1}\right)-d\left(x_{m(k)-1}, x_{m(k)}\right) \\
& -d\left(y_{m(k)-1}, y_{m(k)}\right) \leq d\left(x_{n(k)-1}, x_{m(k)-1}\right)+d\left(y_{n(k)-1}, y_{m(k)-1}\right) \\
& <\epsilon+\left[d\left(x_{m(k)}, x_{m(k)-1}\right)+d\left(y_{m(k)}, y_{m(k)-1}\right)\right] .
\end{aligned}
$$

Taking limit as $k \rightarrow \infty$ in the above inequality and using (3.11) and (3.13), we have

$$
\lim _{k \rightarrow \infty}\left[d\left(x_{m(k)-1}, x_{n(k)-1}\right)+d\left(y_{m(k)-1}, y_{n(k)-1}\right)\right]=\epsilon .
$$

Now,

$$
\begin{aligned}
& d\left(x_{n(k)}, x_{m(k)}\right)+d\left(y_{n(k)}, y_{m(k)}\right) \\
& \leq\left[d\left(x_{n(k)}, x_{n(k)-1}\right)+d\left(y_{n(k)}, y_{n(k)-1}\right)\right]+\left[d\left(x_{n(k)-1}, x_{m(k)}\right)+d\left(y_{n(k)-1}, y_{m(k)}\right)\right] \\
& \leq\left[d\left(x_{n(k)}, x_{n(k)-1}\right)+d\left(y_{n(k)}, y_{n(k)-1}\right)\right]+\left[d\left(x_{n(k)-1}, x_{m(k)-1}\right)+d\left(y_{n(k)-1}, y_{m(k)-1}\right)\right] \\
& +\left[d\left(x_{m(k)-1}, x_{m(k)}\right)+d\left(y_{m(k)-1}, y_{m(k)}\right)\right] .
\end{aligned}
$$

Taking limit as $k \rightarrow \infty$ in the above inequality and using (3.11), (3.13) and (3.14), we get

$$
\lim _{k \rightarrow \infty}\left[d\left(x_{n(k)-1}, x_{m(k)}\right)+d\left(y_{n(k)-1}, y_{m(k)}\right)\right]=\epsilon .
$$

Using (3.3) and the transitivity assumption of $R$, we have

$$
\left(x_{m(k)-1}, x_{n(k)-1}\right) \in R \text { and }\left(y_{n(k)-1}, y_{m(k)-1}\right) \in R .
$$

Applying (3.1), we have

$$
\begin{aligned}
d\left(x_{m(k)}, x_{n(k)}\right) & =d\left(F\left(x_{m(k)-1}, y_{m(k)-1}\right), F\left(x_{n(k)-1}, y_{n(k)-1}\right)\right) \\
& \leq \beta\left(M\left(x_{m(k)-1}, y_{m(k)-1}, x_{n(k)-1}, y_{n(k)-1}\right)\right) \\
& M\left(x_{m(k)-1}, y_{m(k)-1}, x_{n(k)-1}, y_{n(k)-1}\right)
\end{aligned}
$$


where

$$
\begin{aligned}
& M\left(x_{m(k)-1}, y_{m(k)-1}, x_{n(k)-1}, y_{n(k)-1}\right) \\
= & \max \left\{\frac{d\left(x_{m(k)-1}, x_{n(k)-1}\right)+d\left(y_{m(k)-1}, y_{n(k)-1}\right)}{2},\right. \\
& \frac{d\left(x_{m(k)-1}, F\left(x_{m(k)-1}, y_{m(k)-1}\right)\right)+d\left(y_{m(k)-1}, F\left(y_{m(k)-1}, x_{m(k)-1}\right)\right)}{2}, \\
& \frac{d\left(x_{n(k)-1}, F\left(x_{n(k)-1}, y_{n(k)-1}\right)\right)+d\left(y_{n(k)-1}, F\left(y_{n(k)-1}, x_{n(k)-1}\right)\right)}{2}, \\
& \left.\frac{d\left(x_{n(k)-1}, F\left(x_{m(k)-1}, y_{m(k)-1}\right)\right)+d\left(y_{n(k)-1}, F\left(y_{m(k)-1}, x_{m(k)-1}\right)\right)}{2}\right\} \\
= & \max \left\{\frac{d\left(x_{m(k)-1}, x_{n(k)-1}\right)+d\left(y_{m(k)-1}, y_{n(k)-1}\right)}{2}, \frac{d\left(x_{m(k)-1}, x_{m(k)}\right)+d\left(y_{m(k)-1}, y_{m(k)}\right)}{2},\right. \\
& \left.\frac{d\left(x_{n(k)-1}, x_{n(k)}\right)+d\left(y_{n(k)-1}, y_{n(k)}\right)}{2}, \frac{d\left(x_{n(k)-1}, x_{m(k)}\right)+d\left(y_{n(k)-1}, y_{m(k)}\right)}{2}\right\} .
\end{aligned}
$$

Similarly, we show that

$$
\begin{aligned}
d\left(y_{m(k)}, y_{n(k)}\right)= & d\left(F\left(y_{m(k)-1}, x_{m(k)-1}\right), F\left(y_{n(k)-1}, x_{n(k)-1}\right)\right) \\
\leq & \beta\left(M\left(y_{m(k)-1}, x_{m(k)-1}, y_{n(k)-1}, x_{n(k)-1}\right)\right) \\
& M\left(y_{m(k)-1}, x_{m(k)-1}, y_{n(k)-1}, x_{n(k)-1}\right) \\
= & \beta\left(M\left(x_{m(k)-1}, y_{m(k)-1}, x_{n(k)-1}, y_{n(k)-1}\right)\right) \\
& M\left(x_{m(k)-1}, y_{m(k)-1}, x_{n(k)-1}, y_{n(k)-1}\right) .
\end{aligned}
$$

Combining (3.16) and (3.18), we have

$$
\begin{aligned}
d\left(x_{m(k)}, x_{n(k)}\right)+d\left(y_{m(k)}, y_{n(k)}\right) \leq & 2 \beta\left(M\left(x_{m(k)-1}, y_{m(k)-1}, x_{n(k)-1}, y_{n(k)-1}\right)\right) \\
& M\left(x_{m(k)-1}, y_{m(k)-1}, x_{n(k)-1}, y_{n(k)-1}\right) .
\end{aligned}
$$

Taking limit as $k \rightarrow \infty$ in (3.17) and using (3.11), (3.14) and (3.15), we have

$$
\lim _{k \rightarrow \infty} M\left(x_{m(k)-1}, y_{m(k)-1}, x_{n(k)-1}, y_{n(k)-1}\right)=\max \left\{\frac{\epsilon}{2}, 0,0, \frac{\epsilon}{2}\right\}=\frac{\epsilon}{2} .
$$

Taking limit supremum in (3.19) and using (3.13), (3.20), we have

$$
\begin{aligned}
\epsilon & \leq 2 \limsup _{k \rightarrow \infty} \beta\left(M\left(x_{m(k)-1}, y_{m(k)-1}, x_{n(k)-1}, y_{n(k)-1}\right)\right) \frac{\epsilon}{2} \\
& =\epsilon \limsup _{k \rightarrow \infty} \beta\left(M\left(x_{m(k)-1}, y_{m(k)-1}, x_{n(k)-1}, y_{n(k)-1}\right)\right) .
\end{aligned}
$$

Using (3.21) and the property of $\beta$, we have

$$
1 \leq \limsup _{k \rightarrow \infty} \beta\left(M\left(x_{m(k)-1}, y_{m(k)-1}, x_{n(k)-1}, y_{n(k)-1}\right)\right) \leq 1,
$$

that is, $\lim _{\sup _{k \rightarrow \infty}} \beta\left(M\left(x_{m(k)-1}, y_{m(k)-1}, x_{n(k)-1}, y_{n(k)-1}\right)\right)=1$. Then it follows by the property of $\beta$ that $\lim _{k \rightarrow \infty} M\left(x_{m(k)-1}, y_{m(k)-1}, x_{n(k)-1}, y_{n(k)-1}\right)=\frac{\epsilon}{2}=0$, that is, $\epsilon=0$ which is a contradiction. Therefore, $\left\{x_{n}\right\}$ and $\left\{y_{n}\right\}$ are both Cauchy sequences in $X$. As $X$ is complete, there exist 
$x, y \in X$ such that

$$
\lim _{n \rightarrow \infty} x_{n}=x \text { and } \quad \lim _{n \rightarrow \infty} y_{n}=y .
$$

Now we show that $(x, y)$ is a coupled fixed point of $F$. If possible let $(x, y)$ be not a coupled fixed point of $F$. Then either $x \neq F(x, y)$ or $y \neq F(y, x)$, that is, either, $d(x, F(x, y)) \neq 0$ or $d(y, F(y, x)) \neq 0$, that is, $d(x, F(x, y))+d(y, F(y, x))>0$. Using (3.3), (3.22) and R-regularity property of the space, we have

$$
\left(x_{n}, x\right) \in R \quad \text { and } \quad\left(y, y_{n}\right) \in R \text {. }
$$

By (3.1) and (3.23), we have

$$
\begin{aligned}
d\left(x_{n+1}, F(x, y)\right) & =d\left(F\left(x_{n}, y_{n}\right), F(x, y)\right) \\
& \leq \beta\left(M\left(x_{n}, y_{n}, x, y\right)\right) M\left(x_{n}, y_{n}, x, y\right)
\end{aligned}
$$

where

$$
\begin{aligned}
M\left(x_{n}, y_{n}, x, y\right)= & \max \left\{\frac{d\left(x_{n}, x\right)+d\left(y_{n}, y\right)}{2}, \frac{d\left(x_{n}, F\left(x_{n}, y_{n}\right)\right)+d\left(y_{n}, F\left(y_{n}, x_{n}\right)\right)}{2},\right. \\
& \left.\frac{d(x, F(x, y))+d(y, F(y, x))}{2}, \frac{d\left(x, F\left(x_{n}, y_{n}\right)\right)+d\left(y, F\left(y_{n}, x_{n}\right)\right)}{2}\right\} \\
= & \max \left\{\frac{d\left(x_{n}, x\right)+d\left(y_{n}, y\right)}{2}, \frac{d\left(x_{n}, x_{n+1}\right)+d\left(y_{n}, y_{n+1}\right)}{2}\right. \\
& \left.\frac{d(x, F(x, y))+d(y, F(y, x))}{2}, \frac{d\left(x, x_{n+1}\right)+d\left(y, y_{n+1}\right)}{2}\right\} .
\end{aligned}
$$

Similarly, we show that

$$
\begin{aligned}
d\left(y_{n+1}, F(y, x)\right) & \left.=d\left(F\left(y_{n}, x_{n}\right), F(y, x)\right) \leq \beta\left(M\left(y_{n}, x_{n}, y, x\right)\right) M\left(y_{n}, x_{n}, y, x\right)\right) \\
& =\beta\left(M\left(x_{n}, y_{n}, x, y\right)\right) M\left(x_{n}, y_{n}, x, y\right) .
\end{aligned}
$$

Combining (3.24) and (3.26), we have

$$
d\left(x_{n+1}, F(x, y)\right)+d\left(y_{n+1}, F(y, x)\right) \leq 2 \beta\left(M\left(x_{n}, y_{n}, x, y\right)\right) M\left(x_{n}, y_{n}, x, y\right) .
$$

Taking limit as $n \rightarrow \infty$ in (3.25), we have

$$
\begin{aligned}
\lim _{n \rightarrow \infty} M\left(x_{n}, y_{n}, x, y\right) & =\max \left\{0,0, \frac{d(x, F(x, y))+d(y, F(y, x))}{2}, 0\right\} \\
& =\frac{d(x, F(x, y))+d(y, F(y, x))}{2} .
\end{aligned}
$$

Taking limit supremum in (3.27) and using (3.22) and (3.28), we have

$$
d\left(x, F(x, y)+d(y, F(y, x)) \leq\left[d(x, F(x, y)+d(y, F(y, x))] \limsup _{n \rightarrow \infty} \beta\left(M\left(x_{n}, y_{n}, x, y\right)\right) .\right.\right.
$$

As explained earlier, we have from (3.29) that

$$
1 \leq \limsup _{n \rightarrow \infty} \beta\left(M\left(x_{n}, y_{n}, x, y\right)\right) \leq 1
$$


that is, $\limsup _{n \rightarrow \infty} \beta\left(M\left(x_{n}, y_{n}, x, y\right)\right)=1$. By a property of $\beta$ we have that

$$
\lim _{n \rightarrow \infty} M\left(x_{n}, y_{n}, x, y\right)=\frac{d(x, F(x, y))+d(y, F(y, x))}{2}=0,
$$

that is, $d(x, F(x, y))+d(y, F(y, x))=0$, which contradicts our assumption. Therefore, $d(x, F(x, y))=d(y, F(y, x))=0$, that is, $x=F(x, y)$ and $y=F(y, x)$, that is, $(x, y)$ is a coupled fixed point of $F$.

Remark 3.2. Our result is a generalization of the result of Bhaskar and Lakshmikantam (in [15]) and of the result of Choudhury and Kundu (in [8]).

If $R$ is taken to be a partial ordered relation, then we have the following corollary:

Corollary 3.3. Let $(X, d)$ be a complete metric space with a partial order $\preceq$ on it such that $X$ has regular property [that is, if $\left\{x_{n}\right\}$ is a monotone convergent sequence with limit $x$, then $x_{n} \preceq x$ or $x \preceq x_{n}$, according as the sequence is increasing or decreasing]. Suppose that $F: X \times X \rightarrow X$ is a dominated map [that is, $x \preceq F(x, y)$ and $F(y, x) \preceq y$, for any $(x, y) \in X \times X$ ] and there exists $\beta \in \boldsymbol{B}^{*}$ such that (3.1) of Theorem 3.1 is satisfied for all $(x, y),(u, v) \in X \times X$ with $[x \preceq u$ and $v \preceq y]$ or $[u \preceq x$ and $y \preceq v]$. Then $F$ has a coupled fixed point.

If $R$ is taken to be the universal relation, that is, $R=X \times X$, we have the following corollary:

Corollary 3.4. Let $(X, d)$ be a complete metric space and $F: X \times X \rightarrow X$. Suppose there exists $\beta \in \boldsymbol{B}^{*}$ such that (3.1) of Theorem 3.1 is satisfied for all $(x, y),(u, v) \in X \times X$. Then $F$ has a coupled fixed point.

Theorem 3.5. In addition to the hypothesis of Theorem 3.1, suppose that both $R$ and $R^{-1}$ are directed. Then $F$ has a unique coupled fixed point.

Proof. By Theorem 3.1, the set of coupled fixed points of $F$ is nonempty. If possible, let $(x, y)$ and $\left(x^{*}, y^{*}\right)$ be two coupled fixed points of $F$. Then $x=F(x, y) ; y=F(y, x)$ and $x^{*}=$ $F\left(x^{*}, y^{*}\right) ; y^{*}=F\left(y^{*}, x^{*}\right)$. Our aim is to show that $x=x^{*}$ and $y=y^{*}$. By the directed property of $R$ and $R^{-1}$, there exist $u \in X$ and $v \in X$ such that $(x, u) \in R ;\left(x^{*}, u\right) \in R$ and $(y, v) \in R^{-1} ;\left(y^{*}, v\right) \in R^{-1}$, that is $(x, u) \in R ;\left(x^{*}, u\right) \in R$ and $(v, y) \in R ;\left(v, y^{*}\right) \in R$. Put $u_{0}=u$ and $v_{0}=v$. Then $\left(x, u_{0}\right) \in R$ and $\left(v_{0}, y\right) \in R$. Let $u_{1}=F\left(u_{0}, v_{0}\right)$ and $v_{1}=F\left(v_{0}, u_{0}\right)$. Similarly, as in the proof of Theorem 3.1, we inductively define two sequences $\left\{u_{n}\right\}$ and $\left\{v_{n}\right\}$ such that

$$
u_{n+1}=F\left(u_{n}, v_{n}\right) \text { and } v_{n+1}=F\left(v_{n}, u_{n}\right), \text { for all } n \geq 0 .
$$

As $F$ is $R$-dominated, we have

$$
\left(u_{n}, u_{n+1}\right) \in R \text { and }\left(v_{n+1}, v_{n}\right) \in R \text {, for all } n \geq 0 \text {. }
$$


Arguing similarly as in proof of Theorem 3.1, we prove that $\left\{u_{n}\right\}$ and $\left\{v_{n}\right\}$ are two Cauchy sequences in $X$ and there exists $p$ and $q \in X$ such that

$$
\lim _{n \rightarrow \infty} u_{n}=p \text { and } \lim _{n \rightarrow \infty} v_{n}=q .
$$

Now we show that $x=p$ and $y=q$, that is, $d(x, p)+d(y, q)=0$.

If possible, suppose that $d(x, p)+d(y, q) \neq 0$. We claim that

$$
\left(x, u_{n}\right) \in R \text { and }\left(v_{n}, y\right) \in R, \text { for all } n \geq 0 .
$$

As $\left(x, u_{0}\right) \in R,\left(u_{0}, u_{1}\right) \in R$ and $\left(v_{1}, v_{0}\right) \in R,\left(v_{0}, y\right) \in R$, by the transitivity property of $R$, we have $\left(x, u_{1}\right) \in R$ and $\left(v_{1}, y\right) \in R$. Therefore, our claim is true for $n=1$. Assume that (3.33) is true for some $m>1$, that is, $\left(x, u_{m}\right) \in R$ and $\left(v_{m}, y\right) \in R$. By $(3.31),\left(u_{m}, u_{m+1}\right) \in R$ and $\left(v_{m+1}, u_{m}\right) \in R$. The transitivity property of $R$ guarantees that $\left(x, u_{m+1}\right) \in R$ and $\left(v_{m+1}, y\right) \in R$ and this proves our claim. Using (3.1) and (3.33), we have for all $n \geq 0$ that

$$
\begin{aligned}
d\left(x, u_{n+1}\right) & =d\left(F(x, y), F\left(u_{n}, v_{n}\right)\right) \\
& \leq \beta\left(M\left(x, y, u_{n}, v_{n}\right)\right) M\left(x, y, u_{n}, v_{n}\right)
\end{aligned}
$$

where

$$
\begin{aligned}
M\left(x, y, u_{n}, v_{n}\right)= & \max \left\{\frac{d\left(x, u_{n}\right)+d\left(y, v_{n}\right)}{2}, \frac{d(x, F(x, y))+d(y, F(y, x))}{2},\right. \\
& \left.\frac{d\left(u_{n}, F\left(u_{n}, v_{n}\right)\right)+d\left(v_{n}, F\left(v_{n}, u_{n}\right)\right)}{2}, \frac{d\left(u_{n}, F(x, y)\right)+d\left(v_{n}, F(y, x)\right)}{2}\right\} \\
= & \max \left\{\frac{d\left(x, u_{n}\right)+d\left(y, v_{n}\right)}{2}, 0, \frac{d\left(u_{n}, u_{n+1}\right)+d\left(v_{n}, v_{n+1}\right)}{2}\right. \\
& \left.\frac{d\left(u_{n}, x\right)+d\left(v_{n}, y\right)}{2}\right\} .
\end{aligned}
$$

Similarly, we show that

$$
\begin{aligned}
d\left(y, v_{n+1}\right) & =d\left(F(y, x), F\left(v_{n}, u_{n}\right)\right) \leq \beta\left(M\left(y, x, v_{n}, u_{n}\right)\right) M\left(y, x, v_{n}, u_{n}\right) \\
& =\beta\left(M\left(x, y, u_{n}, v_{n}\right)\right) M\left(x, y, u_{n}, v_{n}\right) .
\end{aligned}
$$

Combining (3.34) and (3.36), we have

$$
d\left(x, u_{n+1}\right)+d\left(y, v_{n+1}\right) \leq 2 \beta\left(M\left(x, y, u_{n}, v_{n}\right)\right) M\left(x, y, u_{n}, v_{n}\right) .
$$

Taking limit in (3.35) as $n \rightarrow \infty$ and using (3.32), we have

$$
\lim _{n \rightarrow \infty} M\left(x, y, u_{n}, v_{n}\right)=\frac{d(x, p)+d(y, q)}{2} .
$$

Taking limit supremum as $n \rightarrow \infty$ in (3.37) and using (3.32), (3.38), we have

$$
d(x, p)+d(y, q) \leq[d(x, p)+d(y, q)] \limsup _{n \rightarrow \infty} \beta\left(M\left(x, y, u_{n}, v_{n}\right)\right)
$$


which implies that

$$
1 \leq \limsup _{n \rightarrow \infty} \beta\left(M\left(x, y, u_{n}, v_{n}\right)\right) \leq 1
$$

that is, $\limsup _{n \rightarrow \infty} \beta\left(M\left(x, y, u_{n}, v_{n}\right)\right)=1$. By a property of $\beta$ we have that

$$
\lim _{n \rightarrow \infty} M\left(x, y, u_{n}, v_{n}\right)=\frac{d(x, p)+d(y, q)}{2}=0,
$$

that is, $d(x, p)+d(y, q)=0$, which contradicts our assumption that $d(x, p)+d(y, q) \neq 0$. Therefore, $d(x, p)+d(y, q)=0$, that is, $d(x, p)=d(y, q)=0$, that is,

$$
x=p \text { and } y=q .
$$

Similarly, we can show that

$$
x^{*}=p \text { and } y^{*}=q .
$$

From (3.41) and (3.42), we have $x=x^{*}$ and $y=y^{*}$. Therefore, the coupled fixed point of $F$ is unique.

We present the following illustrative example in support of Theorems 3.1.

Example 3.6. Take the metric space $X=[0,1]$ with usual metric $d$. Let $\beta:[0, \infty) \rightarrow[0,1)$ be defined as $\beta(t)=\frac{\ln (1+t)}{t}$, if $t>0$ and $\beta(t)=0$, if $t=0$. Define $F: X \times X \rightarrow X$ by $F(x, y)=\ln \left(1+\frac{x+y}{2}\right)$, for all $(x, y) \in X \times X$ and binary relation $R$ by $R=\{(x, y): 0 \leq x \leq$ $1 ; 0 \leq y \leq \ln 2$ or $0 \leq x \leq \ln 2 ; 0 \leq y \leq 1\}$.

Then we see that $X$ is regular with respect to $R$ and $T$ is $R$-dominated. Let $(x, y),(u, v) \in$ $X \times X$ with $(x, u) \in R$ and $(v, y) \in R$. Then $[x \in[0,1]$ or $x \in[0, \ln 2]] ;[u \in[0,1]$ or $u \in[0, \ln 2]] ;[y \in[0,1]$ or $y \in[0, \ln 2]]$ and $[v \in[0,1]$ or $v \in[0, \ln 2]]$. Now for those values of $x, y, y, u$ and $v$, we obtain

$$
\begin{aligned}
& d(F(x, y), F(u, v))=d\left(\ln \left(1+\frac{x+y}{2}\right), \ln \left(1+\frac{u+v}{2}\right)\right) \\
& =\left|\ln \left(1+\frac{x+y}{2}\right)-\ln \left(1+\frac{u+v}{2}\right)\right|=\left|\ln \left(\frac{1+\frac{x+y}{2}}{1+\frac{u+v}{2}}\right)\right| \\
& \left.=\left|\ln \left(1+\frac{\frac{x+y}{2}-\frac{u+v}{2}}{1+\frac{u+v}{2}}\right)\right| \leq|\ln | 1+\frac{\left|\frac{x+y}{2}-\frac{u+v}{2}\right|}{1+\frac{u+v}{2}} \mid\right) \mid \\
& \leq\left|\ln \left(1+\left|\frac{x+y}{2}-\frac{u+v}{2}\right|\right)\right| \leq\left|\ln \left(1+\frac{|u-x|+|v-y|}{2}\right)\right| \\
& =\ln \left(1+\frac{|u-x|+|v-y|}{2}\right) \leq \ln (1+M(x, y, u, v)) \\
& =\frac{\ln (1+M(x, y, u, v))}{M(x, y, u, v)} M(x, y, u, v)=\beta(M(x, y, u, v)) M(x, y, u, v) .
\end{aligned}
$$


It follows that the inequality in Theorem 3.1 is satisfied for all $(x, y),(u, v) \in X \times X$ with $(x, u) \in R$ and $(v, y) \in R$. Here all the conditions of Theorem 3.1 are satisfied and $(0,0)$ is a coupled fixed point of $F$.

\section{Well-Posedness}

We use the following assumption to assure the well-posedness via $R$-dominated mapping.

(A) If $\left(x^{*}, y^{*}\right)$ is any solution of the problem $(\mathrm{P})$, that is, of $(2.1)$ and $\left\{\left(x_{n}, y_{n}\right)\right\}$ is any sequence in $X \times X$ for which $\lim _{n \rightarrow \infty} d\left(x_{n}, F\left(x_{n}, y_{n}\right)\right)=\lim _{n \rightarrow \infty} d\left(y_{n}, F\left(y_{n}, x_{n}\right)\right)=0$, then $\left(x^{*}, x_{n}\right) \in R$ and $\left(y_{n}, y^{*}\right) \in R$, for all $n$.

Theorem 4.1. In addition to the hypothesis of Theorem 3.5, suppose that the assumption (A) holds. Then the coupled fixed point problem $(P)$ is well-posed.

Proof. By Theorem 3.5, $F$ has a unique coupled fixed point $\left(x^{*}, y^{*}\right)$ (say). Then $\left(x^{*}, y^{*}\right)$ is a solution of (2.1), that is, $x^{*}=F\left(x^{*}, y^{*}\right)$ and $y^{*}=F\left(y^{*}, x^{*}\right)$. Let $\left\{\left(x_{n}, y_{n}\right)\right\}$ be any sequence in $X \times X$ for which $\limsup _{n \rightarrow \infty}\left[d\left(x_{n}, x^{*}\right)+d\left(y_{n}, y^{*}\right)\right]$ is finite and $\lim _{n \rightarrow \infty} d\left(x_{n}, F\left(x_{n}, y_{n}\right)\right)=$ $\lim _{n \rightarrow \infty} d\left(y_{n}, F\left(y_{n}, x_{n}\right)\right)=0$. Then there exists a nonnegative real number $M$ such that $\limsup _{n \rightarrow \infty}\left[d\left(x^{*}, x_{n}\right)+d\left(y^{*}, y_{n}\right)\right]=M$ and also by the assumption $(\mathrm{A}),\left(x^{*}, x_{n}\right) \in R$ and $\left(y_{n}, y^{*}\right) \in$ $R$, for all $n$. Using (3.1), we have

$$
\begin{aligned}
d\left(x_{n}, x^{*}\right) & =d\left(x_{n}, F\left(x^{*}, y^{*}\right)\right) \leq d\left(x_{n}, F\left(x_{n}, y_{n}\right)+d\left(F\left(x^{*}, y^{*}\right), F\left(x_{n}, y_{n}\right)\right)\right. \\
& \leq \beta\left(M\left(x^{*}, y^{*}, x_{n}, y_{n}\right)\right) M\left(x^{*}, y^{*}, x_{n}, y_{n}\right)+d\left(x_{n}, F\left(x_{n}, y_{n}\right)\right)
\end{aligned}
$$

where

$$
\begin{aligned}
M\left(x^{*}, y^{*}, x_{n}, y_{n}\right)= & \max \left\{\frac{d\left(x^{*}, x_{n}\right)+d\left(y^{*}, y_{n}\right)}{2}, \frac{d\left(x^{*}, F\left(x^{*}, y^{*}\right)\right)+d\left(y^{*}, F\left(y^{*}, x^{*}\right)\right)}{2},\right. \\
& \left.\frac{d\left(x_{n}, F\left(x_{n}, y_{n}\right)\right)+d\left(y_{n}, F\left(y_{n}, x_{n}\right)\right)}{2}, \frac{d\left(x_{n}, F\left(x^{*}, y^{*}\right)\right)+d\left(y_{n}, F\left(y^{*}, x^{*}\right)\right)}{2}\right\} \\
= & \max \left\{\frac{d\left(x^{*}, x_{n}\right)+d\left(y^{*}, y_{n}\right)}{2}, 0, \frac{d\left(x_{n}, F\left(x_{n}, y_{n}\right)\right)+d\left(y_{n}, F\left(y_{n}, x_{n}\right)\right)}{2},\right. \\
& \left.\frac{d\left(x_{n}, x^{*}\right)+d\left(y_{n}, y^{*}\right)}{2}\right\} .
\end{aligned}
$$

Similarly, we can show that

$$
\begin{aligned}
d\left(y_{n}, y^{*}\right) & \leq \beta\left(M\left(y^{*}, x^{*}, y_{n}, x_{n}\right)\right) M\left(y^{*}, x^{*}, y_{n}, x_{n}\right)+d\left(y_{n}, F\left(y_{n}, x_{n}\right)\right) \\
& \leq \beta\left(M\left(x^{*}, y^{*}, x_{n}, y_{n}\right)\right) M\left(x^{*}, y^{*}, x_{n}, y_{n}\right)+d\left(y_{n}, F\left(y_{n}, x_{n}\right)\right) .
\end{aligned}
$$

Combining (4.1) and (4.3), we have

$$
\begin{aligned}
d\left(x_{n}, x^{*}\right)+d\left(y_{n}, y^{*}\right) & \leq 2 \beta\left(M\left(x^{*}, y^{*}, x_{n}, y_{n}\right)\right) M\left(x^{*}, y^{*}, x_{n}, y_{n}\right) \\
& +d\left(x_{n}, F\left(x_{n}, y_{n}\right)\right)+d\left(y_{n}, F\left(y_{n}, x_{n}\right)\right) .
\end{aligned}
$$


Taking limit supremum as $n \rightarrow \infty$ in (4.2), we have

$$
\limsup _{n \rightarrow \infty} M\left(x^{*}, y^{*}, x_{n}, y_{n}\right)=\frac{M}{2} \text {. }
$$

If possible, suppose that $\limsup _{n \rightarrow \infty}\left[d\left(x^{*}, x_{n}\right)+d\left(y^{*}, y_{n}\right)\right]=M \neq 0$. Then $M>0$. Taking limit supremum as $n \rightarrow \infty$ in (4.4) and using (4.5), we have

$$
M \leq M \limsup _{n \rightarrow \infty} \beta\left(M\left(x^{*}, y^{*}, x_{n}, y_{n}\right)\right) \text {, that is, } 1 \leq \limsup _{n \rightarrow \infty} \beta\left(M\left(x^{*}, y^{*}, x_{n}, y_{n}\right)\right) \leq 1
$$

Then $\lim \sup _{n \rightarrow \infty} \beta\left(M\left(x^{*}, y^{*}, x_{n}, y_{n}\right)\right)=1$. By a property of $\beta, \lim _{n \rightarrow \infty} M\left(x^{*}, y^{*}, x_{n}, y_{n}\right)=0$, that is, $\lim _{n \rightarrow \infty}\left[d\left(x_{n}, x^{*}\right)+d\left(y_{n}, y^{*}\right)\right]=0$ which is a contradiction. Hence we have $\limsup _{n \rightarrow \infty}\left[d\left(x^{*}, x_{n}\right)+d\left(y^{*}, y_{n}\right)\right]=0$. Then we have $0 \leq \liminf _{n \rightarrow \infty}\left[d\left(x^{*}, x_{n}\right)+d\left(y^{*}, y_{n}\right)\right] \leq$ $\limsup _{n \rightarrow \infty}\left[d\left(x^{*}, x_{n}\right)+d\left(y^{*}, y_{n}\right)\right]=0$ which implies that $\lim _{n \rightarrow \infty}\left[d\left(x^{*}, x_{n}\right)+d\left(y^{*}, y_{n}\right)\right]=0$. It follows that $\lim _{n \rightarrow \infty} d\left(x_{n}, x^{*}\right)=\lim _{n \rightarrow \infty} d\left(y_{n}, y^{*}\right)=0$, that is, $x_{n} \rightarrow x^{*}$ and $y_{n} \rightarrow y^{*}$ as $n \rightarrow \infty$. Hence the coupled fixed point problem (P) is well-posed.

\section{Some results for $\alpha$-dominated mapping}

Coupled $\alpha$-dominated mappings are defined here and are conceptual extensions of mappings with admissibility conditions. Various types of admissibility conditions have been used in fixed point theory in works like $[10,11,19,29,31]$.

Definition 5.1. Let $X$ be a nonempty set and $\alpha: X \times X \rightarrow \mathbb{R}$ be a mapping. A mapping $F: X \times X \rightarrow X$ is said to be $\alpha$-dominated if $\alpha(x, F(x, y)) \geq 1$ and $\alpha(y, F(y, x)) \geq 1$, for $(x, y) \in X \times X$.

Definition 5.2. Let $X$ be a nonempty set and $\alpha: X \times X \rightarrow \mathbb{R}$ be a mapping. Then $\alpha$ is said to have triangular property if for $x, y, z \in X, \alpha(x, y) \geq 1$ and $\alpha(y, z) \geq 1$ imply $\alpha(x, z) \geq 1$.

Definition 5.3. Let $(X, d)$ be a metric space and $\alpha: X \times X \rightarrow \mathbb{R}$ be a mapping. Then $X$ is said to have $\alpha$-regular property if for every convergent sequence $\left\{x_{n}\right\}$ with limit $x \in X, \alpha\left(x_{n}, x_{n+1}\right) \geq 1$, for all $n$ implies $\alpha\left(x_{n}, x\right) \geq 1$, for all $n$.

Theorem 5.4. Let $(X, d)$ be a complete metric space and $\alpha: X \times X \rightarrow \mathbb{R}$ be a mapping such that $X$ has $\alpha$-regular property and $\alpha$ has triangular property. Suppose that $F: X \times X \rightarrow X$ be a $\alpha$-dominated mapping and there exists $\beta \in \boldsymbol{B}^{*}$ such that (3.1) of Theorem 3.1 is satisfied for all $(x, y),(u, v) \in X \times X$ with $\alpha(x, u) \geq 1$ and $\alpha(y, v) \geq 1$. Then $F$ has a coupled fixed point.

Proof. Define a binary relation $R$ on $X$ as $(x, y) \in R$ if and only if $\alpha(x, y) \geq 1$ or $\alpha(y, x) \geq 1$. Then (i) $\alpha(x, u) \geq 1$ and $\alpha(y, v) \geq 1$ imply $(x, u) \in R$ and $(v, y) \in R$, (ii) $\alpha(x, F(x, y)) \geq 1$ and $\alpha(y, F(y, x)) \geq 1$ imply $(x, F(x, y)) \in R$ and $(F(y, x), y) \in R$, for $(x, y) \in X \times X$, 
(iii) $\alpha\left(x_{n}, x_{n+1}\right) \geq 1, \alpha\left(x_{n}, x\right) \geq 1$ imply $\left(x_{n}, x_{n+1}\right) \in R,\left(x_{n}, x\right) \in R$, whenever $\left\{x_{n}\right\}$ is a convergent sequence with $x_{n} \rightarrow x$ and $\alpha\left(x_{n}, x_{n+1}\right) \geq 1$. Therefore, all the assumptions reduce to the assumptions of Theorem 3.1. Then by an application of Theorem 3.1, we conclude that $F$ has a coupled fixed point in $X \times X$.

\section{Some results on graphic contraction}

Our present section is on graphic contraction. Fixed point problem on the structures of metric spaces with a graph have appeared in works like $[2,4,12]$.

Let $X$ be a nonempty set and $\Delta:=\{(x, x): x \in X\}$. Let $G$ be a directed graph such that its vertex set $V(G)$ coincides with $X$, that is, $V(G)=X$ and the edge set $E(G)$ contains all loops, that is, $\Delta \subseteq E(G)$. Assume that $G$ has no parallel edges. By $G^{-1}$ we denote the conversion of a graph $G$, that is, the graph obtained from $G$ by reversing the directions of the edges. Thus we have $V\left(G^{-1}\right)=V(G)$ and $E\left(G^{-1}\right)=\{(x, y) \in X \times X:(y, x) \in E(G)\}$. A nonempty set $X$ is said to be endowed with a directed graph $G(V, E)$ if $V(G)=X$ and $\Delta \subseteq E(G)$.

Definition 6.1. Let $X$ be a nonempty set endowed with a graph $G(V, E)$. A mapping $F: X \times X \rightarrow$ $X$ is said to be $G$-dominated if $(x, F(x, y)) \in E$ and $(F(y, x), y) \in E$, for $(x, y) \in X \times X$.

Definition 6.2. Let $X$ be a nonempty set endowed with a graph $G(V, E)$. Then $G$ is said to have transitive property if for $x, y, z \in X,(x, y) \in E$ and $(y, z) \in E$ imply $(x, z) \in E$.

Definition 6.3. Let $(X, d)$ be a metric space endowed with a directed graph $G(V, E)$. Then $X$ is said to have $G$-regular property if for every convergent sequence $\left\{x_{n}\right\}$ with limit $x \in X$, $\left(x_{n}, x_{n+1}\right) \in E$, for all $n$ implies $\left(x_{n}, x\right) \in E$, for all $n$ [or $\left(x_{n+1}, x_{n}\right) \in E$, for all $n$ implies $\left(x, x_{n}\right) \in E$, for all $\left.n\right]$.

Theorem 6.4. Let $(X, d)$ be a complete metric space endowed with a directed graph $G(V, E)$ such that $X$ has $G$-regular property and $G$ has transitive property. Suppose that $F: X \times X \rightarrow X$ is a $G$-dominated mapping and there exists $\beta \in \boldsymbol{B}^{*}$ such that (3.1) of Theorem 3.1 is satisfied for all $(x, y),(u, v) \in X \times X$ with $[(x, u) \in E$ and $(v, y) \in E]$ or $[(u, x) \in E$ and $(y, v) \in E]$. Then $F$ has a coupled fixed point.

Proof. Let us define a relation $R$, by $x R y$ holds if $(x, y) \in E$. As $(x, y) \in E$, for $(x, y) \in X \times X$ implies that $(x, y) \in R$, it is easy to verify that all the assumptions of the theorem reduce to the assumptions of Theorem 3.1. Then by an application of Theorem 3.1, we conclude that $F$ has a coupled fixed point in $X \times X$. 


\section{Application to the solution of system nonlinear integral equations}

In this section, we present an application of our coupled fixed point results derived in Section 3 to establish the existence and uniqueness of a solution of a system of integral equations. We consider a coupled system of two nonlinear integral equations as follows:

$$
\text { and } \left.\begin{array}{rl}
x(t) & =f(t)+\int_{0}^{t} K(t, s) h(t, s, x(s), y(s)) d s \\
y(t) & =f(t)+\int_{0}^{t} K(t, s) h(t, s, y(s), x(s)) d s,
\end{array}\right\}
$$

where $T>0$ be any number, $t, s \in[0, T], K:[0, T] \times[0, T] \rightarrow \mathbb{R}$ be a function, which is the kernel of the integral equations, and the unknown functions $x(t)$ and $y(t)$ take real values.

The reason for the choice of this application is that coupled non-linear equations have their uses in modeling situations of wide variety.

Let $X=C([0, T])$ be the space of all real valued continuous functions defined on $[0, T]$. Here $C([0, T])$ with the metric $d(x, y)=\max _{t \in[0, T]}|x(t)-y(t)|$ is a complete metric space. Assume that this metric space is endowed with the universal relation $U$, that is, $(x, y) \in U$, for all $x, y \in X$. Define a mapping $F: X \times X \rightarrow X$ by

$$
F(x, y)(t)=f(t)+\int_{0}^{t} K(t, s) h(t, s, x(s), y(s)) d s, \text { for all } t, s \in[0, T] .
$$

We designate the following assumptions by $A_{1}, A_{2}$ and $A_{3}$ :

$A_{1}: \quad f \in C([0, T]$ and $h:[0, T] \times[0, T] \times \mathbb{R} \times \mathbb{R} \rightarrow \mathbb{R}$ is a continuous mapping;

$A_{2}:|K(t, s)| \leq q$, where $q>0$ is a fixed number;

$A_{3}:|h(t, s, x, y)-h(t, s, u, v)| \leq \mathcal{M}(t, s, x, y, u, v)$, for all $(x, y),(u, v) \in X \times X$

and $t, s \in[0, T]$, where $\mathcal{M}(t, s, x, y, u, v)=\frac{1}{q T} \ln \left(1+\frac{|x-u|+|y-v|}{2}\right)$.

Theorem 7.1. Let $(X=C([0, T]), d), F, h, K(t, s)$ satisfy the assumptions $A_{1}, A_{2}$ and $A_{3}$. Then system of nonlinear integral equation (7.1) has a solution $(x, y) \in C([0, T]) \times C([0, T])$ and the solution is unique.

Proof. It is trivial to observe that the mapping $F: X \times X \rightarrow X$ defined by (7.2) is a $U$ dominated mapping and $X$ has $U$ regular property, where $U$ is the universal relation. From assumptions $A_{1}, A_{2}$ and $A_{3}$, for all $(x, y),(u, v) \in C([0, T]) \times C([0, T])$, that is, for all $x, y, u, v \in C([0, T])$ and $t, s \in[0, T]$, we have 


$$
\begin{aligned}
&|F(x, y)(t)-F(u, v)(t)|=\left|\int_{0}^{t} K(t, s)[h(t, s, x(s), y(s))-h(t, s, u(s), v(s))] d s\right| \\
& \leq \int_{0}^{t}|K(t, s) \|[h(t, s, x(s), y(s))-h(t, s, u(s), v(s))]| d s \\
& \leq q \times \int_{0}^{t}|[h(t, s, x(s), y(s))-h(t, s, u(s), v(s))]| d s\left[\text { by } A_{2}\right] \\
& \leq q \times \int_{0}^{T}|[h(t, s, x(s), y(s))-h(t, s, u(s), v(s))]| d s \\
& \leq q \times \int_{0}^{T} \mathcal{M}(t, s, x, y, u, v) d s=q \times \int_{0}^{T} \frac{1}{q T} \ln \left(1+\frac{|x-u|+|y-v|}{2}\right) d s \\
&= \int_{0}^{T} \frac{1}{T} \ln \left(1+\frac{|x-u|+|y-v|}{2}\right) d s \leq \int_{0}^{T} \frac{1}{T} \ln \left(1+\frac{d(x, u)+d(y, v)}{2}\right) d s \\
&= \ln \left(1+\frac{d(x, u)+d(y, v)}{2}\right) \int_{0}^{T} \frac{1}{T} d s=\ln \left(1+\frac{d(x, u)+d(y, v)}{2}\right) \\
& \leq \ln (1+M(x, y, u, v))[\operatorname{since} \ln (1+t) \text { is nondecreasing for } t>0] \\
&= \frac{\ln (1+M(x, y, u, v))}{M(x, y, u, v)} M(x, y, u, v)=\beta(M(x, y, u, v)) M(x, y, u, v) \text { where } \\
& \quad \beta(t)=\frac{\ln (1+t)}{t}, \text { if } t>0 \text { and } \beta(t)=0, \text { if } t=0
\end{aligned}
$$

and

$$
\begin{aligned}
M(x, y, u, v)= & \max \left\{\frac{d(x, u)+d(y, v)}{2}, \frac{d(x, F(x, y))+d(y, F(y, x))}{2},\right. \\
& \left.\frac{d(u, F(u, v))+d(v, F(v, u))}{2}, \frac{d(u, F(x, y))+d(v, F(y, x))}{2}\right\} .
\end{aligned}
$$

Hence

$$
d(F(x, y), F(u, v)) \leq \beta(M(x, y, u, v)) M(x, y, u, v) .
$$

Therefore, all the conditions of Theorems 3.1 and 3.5 are satisfied and hence by Theorem 3.1 there exists a coupled fixed point $(x, y)$ in $X \times X$ which, by virtue of Theorem 3.5 , is unique. In other words, the system of integral equations (7.1) under the conditions stipulated in the theorem has a solution which is unique.

Acknowledgement: The suggestions of the learned referee are gratefully acknowledged. 


\section{References}

[1] A. Alam, and M. Imad, "Relation-theoretic contraction principle", J. Fixed Point Theory Appl., vol. 17, pp. 693-702, 2015.

[2] M. R. Alfuraidan, and M. A. Khamsi, "Caristi fixed point theorem in metric spaces with a graph", Abstr. Appl. Anal., Article ID 303484, 5 pages, 2014.

[3] M. S. Asgari, and B. Mousavi, "Coupled fixed point theorems with respect to binary relations in metric spaces", J. Nonlinear Sci. Appl., vol. 8, pp. 153-162, 2015.

[4] I. Beg, A. R. Butt, and S. Radojević, "The contraction principle for set valued mappings on a metric space with a graph", Comput. Math. Appl., vol. 60, pp. 1214-1219, 2010.

[5] D. W. Boyd, and T. S. W. Wong, "On nonlinear contractions", Proc. Amer. Math. Soc., vol. 20, pp. 458-464, 1969.

[6] C. Chifu, and G. Petruşel, "Coupled fixed point results for $(\varphi, G)$-contractions of type (b) in b-metric spaces endowed with a graph", J. Nonlinear Sci. Appl., vol. 10. pp. 671-683, 2017.

[7] B. S. Choudhury, and A. Kundu, "A coupled coincidence point result in partially ordered metric spaces for compatible mappings", Nonlinear Anal., vol. 73, pp. 2524-2531, 2010.

[8] B. S. Choudhury, and A. Kundu, "On coupled generalised Banach and Kannan type contractions", J. Nonlinear Sci. Appl., vol. 5, pp. 259-270, 2012.

[9] B. S. Choudhury, N. Metiya, and M. Postolache, "A generalized weak contraction principle with applications to coupled coincidence point problems", Fixed Point Theory Appl., 152(2013), 2013.

[10] B. S. Choudhury, N. Metiya, and S. Kundu, "Existence and stability results for coincidence points of nonlinear contractions", Facta Universitatis (NÎS) Ser. Math. Inform., vol. 32, no. 4, pp. 469-483, 2017.

[11] B. S. Choudhury, N. Metiya, and S. Kundu, "Fixed point sets of multivalued contractions and stability analysis", Commun. Math. Sci., vol. 2, pp. 163-171, 2018.

[12] M. Dinarvand, "Fixed point results for $(\varphi-\psi)$ contractions in metric spaces endowed with a graph and applications", Matematichki Vesnik, vol. 69, no. 1, pp. 23-38, 2017.

[13] D. Dorić, "Common fixed point for generalized $(\psi, \varphi)$-weak contractions", Appl. Math. Lett., vol. 22, pp. 1896-1900, 2009.

[14] P. N. Dutta, and B. S. Choudhury, "A generalisation of contraction principle in metric spaces", Fixed Point Theory Appl., Article ID 406368, 2008. 
[15] T. Gnana Bhaskar, and V. Lakshmikantham, "Fixed point theorems in partially ordered metric spaces and applications", Nonlinear Anal., vol. 65, pp. 1379-1393, 2006.

[16] M. Geraghty, "On contractive mappings", Proc. Amer. Math. Soc., vol. 40, pp. 604-608, 1973.

[17] D. Guo, and V. Lakshmikantham, "Coupled fixed points of nonlinear operators with applications", Nonlinear Anal., vol. 11, pp. 623-632, 1987.

[18] J. Harjani, B. López, and K. Sadarangani, "Fixed point theorems for mixed monotone operators and applications to integral equations", Nonlinear Anal., vol. 74, pp. 1749-1760, 2011.

[19] N. Hussain, E. Karapinar, P. Salimi, and F. Akbar, " $\alpha$-admissible mappings and related fixed point theorems", J. Inequal. Appl., 114(2013), 2013.

[20] Z. Kadelburg, P. Kumam, S. Radenović, and W. Sintunavarat, "Common coupled fixed point theorems for Geraghty-type contraction mappings using monotone property", Fixed Point Theory Appl., 27(2015), 2015.

[21] E. Karapinar, "Couple fixed point theorems for nonlinear contractions in cone metric spaces", Comput. Math. Appl., vol. 59, pp. 3656-3668, 2010.

[22] M. S. Khan, M. Swaleh, and S. Sessa, "Fixed points theorems by altering distances between the points", Bull. Aust. Math. Soc., vol. 30, pp. 1-9, 1984.

[23] M. S. Khan, M. Berzig, and S. Chandok, "Fixed point theorems in bimetric space endowed with a binary relation and application", Miskolc Mathematical Notes, vol. 16, no. 2, pp. 939-951, 2015.

[24] M. A. Kutbi, and W. Sintunavarat, "Ulam-Hyers stability and well-posedness of fixed point problems for $\alpha-\lambda$-contraction mapping in metric spaces", Abstr. Appl. Anal., Article ID 268230, vol. 2014, 6 pages, 2014.

[25] B. K. Lahiri, and P. Das, "Well-posedness and porosity of a certain class of operators", Demonstratio Math., vol. 1, pp. 170-176, 2005.

[26] X. L Liu, M. Zhou, and B. Damjanović, "Common coupled fixed point theorem for Geraghtytype contraction in partially ordered metric spaces", Journal of Function Spaces, vol. 2018, Article ID 9063267, 11 pages, 2018.

[27] S. Phiangsungnoen, and P. Kumam, "Generalized Ulam-Hyers stability and well-posedness for fixed point equation via $\alpha$-admissibility", J. Inequal. Appl., 418(2014), 2014. 
[28] V. Popa, "Well-posedness of fixed point problem in orbitally complete metric spaces", Stud. Cercet. Stiint., Ser. Mat., vol. 16, pp 209-214, 2006.

[29] P. Salimi, A. Latif, and N. Hussain, "Modified $\alpha-\psi$-contractive mappings with applications", Fixed Point Theory Appl., 151(2013), 2013.

[30] B. Samet, and C. Vetro, "Coupled fixed point theorems for multi-valued nonlinear contraction mappings in partially ordered metric spaces", Nonlinear Anal., vol. 74, no. 12, pp. 4260-4268, 2011.

[31] B. Samet, C. Vetro, and P. Vetro, "Fixed point theorem for $\alpha-\psi$-contractive type mappings", Nonlinear Anal., vol. 75, pp. 2154-2165, 2012.

[32] K. P. R. Sastry, G. V. R. Babu, P. S. Kumar, and B. R. Naidu, "Fixed point theorems for $\alpha$-Geraghty contraction type maps in Generalized metric spaces", MAYFEB Journal of Mathematics, vol. 3, pp. 28-44, 2017.

[33] E. Yolacan, and M. Kir, "New results for $\alpha$-Geraghty type contractive maps with some applications", GU J Sci, vol. 29, no. 3, pp. 651-658, 2016. 